COMUNICAÇÃO CIENTÍFICA

\title{
ATIVIDADE DA CELULASE E $\beta$-GALACTOSIDASE NO ESTUDO DA FIRMEZA DA POLPA DE MAMÕES 'GOLDEN' E 'GRAN GOLDEN'1
}

\author{
CAMILLA ZANOTTI GALLON², SABRINA GARCIA BROETTO ${ }^{3}$, DIOLINA MOURA SILVA ${ }^{4}$
}

RESUMO- O objetivo desse trabalho foi avaliar a ação das enzimas celulase e $\beta$-galactosidase em relação à perda de firmeza dessas cultivares de mamões 'Gran Golden’ e 'Golden' devido a relatos de uma perda de firmeza diferenciada entre as cvs. Os frutos foram armazenados a $25^{\circ} \mathrm{C}$ e analisados diariamente quanto à firmeza da polpa e à atividade enzimática da celulase e $\beta$-galactosidase durante 8 dias. Os resultados de firmeza da polpa e atividade enzimática foram submetidos às análises de correlação e regressão. No $4^{\circ}$ dia pós-colheita os mamões ‘Golden’ apresentaram firmeza média de 60,6 N e os ‘Gran Golden’ 31,1 N e a um aumento da atividade da celulase e da $\beta$-galactosidase. Os dados gerados neste trabalho sugerem que as enzimas celulase e $\beta$-galactosidase atuam diferentemente no processo de perda de firmeza dos frutos das cultivares Golden e Gran Golden. A antecipação na perda de firmeza de ‘Gran Golden’ pode estar relacionada com a maior atividade dessas enzimas.

Termos para indexação: Perda de firmeza, , Enzimas de parede celular, Carica papaya L.

\section{CELLULASE AND $\beta$-GALACTOSIDASE ACTIVITIES IN 'GOLDEN' AND ‘GRAN GOLDEN’ PAPAYA SOFTENING}

\begin{abstract}
It has been reported by orchards from the north of Espírito Santo state that 'Gran Golden' papaya loses firmness faster than 'Golden'. The goal of this work was to evaluate the action of cellulase and $\beta$-galactosidase related to the softening on papaya. The fruits have been stored at $25^{\circ} \mathrm{C}$ and firmness and enzymes activities were daily analyzed during 8 days. The results were submitted to correlation and regression analysis. The activity of cellulase and $\beta$-galactosidase had increased for both cultivars. The $4^{\text {th }}$ postharvest day showed that 'Golden’ firmness was 6.18 while ‘Gran Golden’ was 31.1 N. Fruit softening in 'Gran Golden' was intense and the fruit was very soft at ripe stage. These works show that hydrolytic enzymes cellulase and $\beta$-galactosidase act differently in the softening process in 'Golden' and 'Gran Golden' papaya. The flesh firmness on 'Gran Golden' is related to the increased activity of these enzymes. These results can help to choose which cultivar to produce in relation to shelf-life and fruit quality at commercialization places.

Index terms: Pulp firmness, Cell wall-modifying enzymes, Carica papaya L.
\end{abstract}

O Brasil exportou, em 2007, mamão equivalente a 32 mil toneladas, aproximadamente $35 \mathrm{mi}$ lhões de dólares segundo o Ministério da Agricultura, Pecuária e Abastecimento (MAPA, 2009). O Estado do Espírito Santo destaca-se como responsável por 40 \% da produção nacional de mamão (IBGE, 2006).

Tem sido relatado que a cultivar Gran Golden amadurece mais rapidamente que a cultivar Golden. A compreensão dos processos fisiológicos de amadurecimento dos frutos fornece subsídios para solução de problemas que afetam a produção e a comercialização e contribui para o aumento da produtividade e da melhoria da sua qualidade, desenvolvendo produtos mais aceitáveis e atendendo às exigências do mercado.

A firmeza do mamão pode indicar o seu estádio de maturação ou ponto de colheita e potencial de armazenamento, o que influencia na sua comercialização. Economicamente, a perda de firmeza é um evento pós-colheita muito importante devido aos cuidados necessários durante o manuseio, transporte e armazenamento dos frutos (Manrique \& Lajolo, 2004). A firmeza da polpa de diferentes cultivares de mamoeiros é uma característica relevante na escolha

'(Trabalho 240-08). Recebido em: 22-09-2008. Aceito para publicação em: 04-05-2009.

${ }^{2}$ Bióloga, Msc. em Biologia Vegetal/UFES, Doutoranda em Fisiologia e Bioquímica de Plantas, ESALQ/USP cep: 13.418-900, Piracicaba-SP.millazg@gmail.com

${ }^{3}$ Bióloga, Mestranda em Biologia Vegetal/UFES sabroetto@yahoo.com.br

${ }^{4}$ Prof. Associado, Dsc. em Fisiologia Vegetal, Programa de pós-graduação em Biologia Vegetal, UFES, cep. 29.075-910, Vitória-ES biovegetal@terra.com.br 
da cultivar a ser cultivada em relação ao tempo de prateleira e, consequentemente, à qualidade do mamão no local de comercialização.

O amolecimento tem sido postulado como um desarranjo nas estruturas da parede celular primária e da lamela média do fruto como consequência da atividade de enzimas hidrolíticas nos polímeros de carboidrato (Seymour \& Gross, 1996). As microfibrilas de celulose são desestruturadas pela celulase, enzima capaz de romper as ligações glicosídicas, resultando na liberação de oligossacarídeos, enquanto as pectinas da parede celular são despolimerizadas por enzimas pectinolíticas. Segundo Gross \& Sams (1984), uma das grandes modificações na parede celular de frutos em amadurecimento é a perda de resíduos de galactose, dos polímeros da parede. A $\beta$-galactosidase, uma dessas enzimas, age sobre os polímeros de galactose catalisando a clivagem de resíduos terminais de D-galactose na ligação $\beta-1,4$ (Balasubramaniam et al., 2005).

Em mamões, o mecanismo de ação das enzimas hidrolíticas e pectinolíticas, durante o processo de amadurecimento, está parcialmente esclarecido. Lazan \& Ali (1995) relataram o envolvimento das hidrolases de parede celular na modificação de pectinas e hemiceluloses no amolecimento de mamões da cultivar Eksotika. Esses autores apontaram um aumento de atividade das enzimas $\beta$-galactosidase, poligalacturonase e pectinametilesterase durante o amadurecimento. Fontes et al. (2008) relataram a correlação entre a perda de firmeza e atividade da pectinametilesterase na cultivar Sunrise Solo, porém essa correlação não foi observada para a cultivar Tainung. O objetivo do trabalho foi avaliar o comportamento das enzimas celulase e $\beta$-galactosidase em relação à firmeza da polpa nas cultivares Golden e Gran Golden.

Os frutos do mamoeiro (Carica papaya L.) das cultivares Golden e Gran Golden, com aproximadamente $480 \mathrm{~g}$, oriundos de plantas hermafroditas, foram colhidos de um pomar em Jacupemba, município de Aracruz-ES, e transportados ao Laboratório. Os frutos foram selecionados quanto ao estádio de maturação (casca verde-clara e com duas estrias longitudinais a partir da base do pedúnculo) correspondente ao estádio 2. Após a lavagem com detergente neutro e imersos em solução de hipoclorito de sódio a $5 \%(\mathrm{v} / \mathrm{v})$, por 10 minutos, os frutos foram mantidos a $25 \pm 1^{\circ} \mathrm{C}$ e $85 \pm 5 \%$ UR. Os frutos foram analisados diariamente quanto à firmeza da polpa até o $8^{\circ}$ dia pós-colheita. Posteriormente, amostras de polpa foram congeladas em nitrogênio líquido e mantidas em freezer a $-20^{\circ} \mathrm{C}$ para medições das atividades das enzimas celulase e $\beta$-galactosidase. As análises foram realizadas até o $8^{\circ}$ dia pós-colheita.

A firmeza foi determinada com penetrômetro portátil, ponteira de $8 \mathrm{~mm}$, tomando-se 6 leituras por fruto em partes equidistantes da região equatorial após a retirada da casca. Os resultados foram expressos em Newton (N). As proteínas foram extraídas segundo adaptação da metodologia descrita por Karakurt \& Huber (2003). O conteúdo proteico foi determinado segundo método de Lowry et al. (1951), utilizando soro albumina bovina (BSA - Sigma) como padrão. A atividade da celulase (E.C.3.2.1.4) foi determinada segundo método descrito por Schreier \& HartmannSchreier (1987), e a atividade da $\beta$-galactosidase (E.C. 3.2.1.23) foi determinada segundo Karakurt \& Huber (2003). Os métodos para a determinação de ambas as enzimas foram previamente padronizados para o experimento. $\mathrm{O}$ volume de amostra utilizado e o tempo de reação para obter os resultados observados estão descritos a seguir.

Extração das proteínas totais - amostras de 20 $\mathrm{g}$ da polpa foram homogeneizadas em $40 \mathrm{~mL}$ de etanol gelado (aproximadamente $4^{\circ} \mathrm{C}$ ) durante 2 minutos em mixer. Uma alíquota de $8 \mathrm{~mL}$ do homogenato foi centrifugada (Centrífuga Sigma, 3K30) a 16.000 g por 20 minutos, a $4^{\circ} \mathrm{C}$. O sobrenadante foi descartado, e o precipitado foi homogeneizado com $5 \mathrm{~mL}$ de etanol a $80 \%$ gelado e centrifugado novamente a $16.000 \mathrm{~g}$ por 20 minutos a $4^{\circ} \mathrm{C}$. Após o descarte do sobrenadante, o precipitado foi ressuspendido em $2 \mathrm{~mL}$ de tampão acetato de sódio (25 mM pH 5,0 contendo $\mathrm{NaCl}$ 1,2 M), incubado por 30 minutos, a $4^{\circ} \mathrm{C}$ e, posteriormente, centrifugado a $16.000 \mathrm{~g}$ por 20 minutos, a $4^{\circ} \mathrm{C}$. O sobrenadante obtido, denominado extrato proteico, foi utilizado para dosagens de proteínas totais, necessárias para os cálculos de atividade enzimática específica.

Determinação do conteúdo proteico - a solução diluída de $500 \mu \mathrm{L}$ de água Milli-Q, contendo a amostra foi acrescida de $5 \mathrm{~mL}$ de reagente de cobre (solução de tartarato de sódio e potássio a $2 \%$, sulfato de cobre a $2 \%$ e carbonato de sódio a $3 \%$ em $\mathrm{NaOH}$ 0,1 M, na relação 1:1:48). Após 10 minutos de repouso, adicionaram-se $500 \mu \mathrm{L}$ de reagente de Folin-Dennis (1:2 de água), e a leitura foi realizada após 10 minutos, em absorbância a $660 \mathrm{~nm}$.

Atividade da $\beta$-galactosidase: uma amostra de $350 \mu \mathrm{L}$ da solução de p-nitrofenil- $\beta$ galactopiranosídeo (6,6 mM em tampão acetado de sódio 100 mM, pH 5,2) e $325 \mu \mathrm{L}$ de tampão acetado de sódio $25 \mathrm{mM}$ pH 5,0 contendo $\mathrm{NaCl}$ 1,2 M foram pré-incubados a $37^{\circ} \mathrm{C}$, por 10 minutos. Em seguida, adicionaram-se $25 \mu \mathrm{L}$ do extrato protéico, e o período de incubação para reação enzimática foi de 20 minutos, a $37^{\circ} \mathrm{C}$. Ao final desse tempo, a reação foi 
paralisada pela adição de $1,75 \mathrm{~mL}$ de $\mathrm{NH}_{4} \mathrm{OH} 1 \mathrm{M}$ contendo EDTA 2 mM.

Atividade da celulase: uma amostra de $1 \mathrm{~mL}$ da solução de p-nitrofenil- $\beta$-glicopiranosídeo (4 mM em tampão acetato de sódio $0,1 \mathrm{M}, \mathrm{pH} 5,0$ ) foi préincubada em banho-maria a $37^{\circ} \mathrm{C}$, por 10 minutos. Em seguida, adicionaram-se $100 \mu \mathrm{L}$ do extrato proteico. O período de incubação para a reação enzimática foi de 20 minutos a $37^{\circ} \mathrm{C}$. Ao final desse tempo, a reação foi paralisada pela adição de $2 \mathrm{~mL}$ de tampão $\mathrm{Na}_{2} \mathrm{CO}_{3} /$ $\mathrm{NaH}_{2} \mathrm{CO}_{3}$ 0,2 $\mathrm{M}$ e pH 9,8.

A atividade glicosidásica e galactosidásica foi determinada através da estimativa do p-nitrofenol liberado, que forma um cromógeno amarelo sob condições alcalinas, apresentando $\lambda$ máximo a 400nm e o coeficiente de extinção molar de 18,1 x 10³. Uma unidade enzimática foi definida como a quantidade de enzima que libera 1 ๆmol de p-nitrofenol por grama de proteína por minuto, nas condições da reação.

Para a análise estatística dos dados, adotou-se o delineamento experimental inteiramente casualizado, com parcelas subdivididas. As cultivares determinaram a parcela, e tempo pós-colheita determinou a subparcela. De cada planta, foi colhido 1 fruto totalizando parcelas com 80 frutos de cada cultivar, das quais se constituíram 8 subparcelas com 10 frutos de cada cultivar. A cada uma das 8 subparcelas foi aleatoriamente atribuído um tempo pós-colheita. O processo descrito acima foi repetido 3 vezes, e a média dos dados foram submetidas à análise de variância, pelo teste $\mathrm{F}$, e as médias de firmeza foram comparadas pelo teste de Tukey, ao nível de significância de 5\%. Para o estudo da associação entre a firmeza e a atividade das enzimas, foi calculado o coeficiente de correlação de Pearson. A análise de regressão foi utilizada para o estudo da associação entre a atividade da celulase e da $\beta$-galactosidase e o tempo pós-colheita. Os cálculos foram efetuados através do sistema SAS (software estatístico SAS, versão 9,1- EUA).

Os mamões das cultivares Golden e Gran Golden não apresentaram decréscimo na firmeza entre o primeiro e o segundo dia pós-colheita, durante o armazenamento em temperatura ambiente $(\mathrm{P}<0,05)$. O decréscimo da firmeza acontece para ambas as cultivares a partir do $2^{\circ}$ dia, quando as firmezas médias de 97,8 e de 102,8 $\mathrm{N}$ atingem valores de 7,0 e 5,1 $\mathrm{N}$ no $5^{\circ}$ dia de armazenamento (Tabela 1 ).

O decréscimo na firmeza do mamão 'Gran Golden' foi mais acentuado que o observado para 'Golden', principalmente entre o terceiro e o quarto dia pós-colheita, cujo decréscimo entre esses dias correspondeu a 55\% para a variedade Gran Golden e $29 \%$ para a variedade Golden. Nesses mesmos pe- ríodos de avaliação, também se observou diferença significativa entre as cultivares $(\mathrm{P}<0,05)$. Destacase o $4^{\circ}$ dia em que 'Golden' apresenta firmeza de 60,6 e ‘Gran Golden’ de 31,1 N, diferença de aproximadamente $50 \%$. Observa-se que as cultivares apresentaram um acentuado decréscimo na firmeza entre o $4^{\circ}$ e o $5^{\circ}$ dia, mantendo-se constante a partir desse período, uma vez que os frutos já atingiram o ponto de consumo. Os frutos foram considerados em ponto de consumo quando atingiram firmeza da polpa de $20 \mathrm{~N}$, de acordo com Bron \& Jacomino (2006). Por serem considerados frutos climatéricos, possivelmente houve incremento na respiração como resposta ao aumento na produção de etileno, possivelmente acelerando o decréscimo na firmeza entre o $4^{\circ}$ e o $5^{\circ}$ dia. Fontes et al. (2008) observaram que 'Sunrise Solo' apresentou redução na firmeza mais acentuada que ‘Tainung'. O rápido decréscimo na firmeza é indesejável para a comercialização por levar a perdas pós-colheita consideráveis, já que o fruto atinge seu pleno amadurecimento, muitas vezes, antes de chegar ao local de comercialização.

O aspecto visual da coloração da casca da cultivar Gran Golden apresentava-se completamente amarelado no $4^{\circ}$ dia pós-colheita, e a polpa apresentava-se pronta para consumo. Apesar do acentuado decréscimo da firmeza da cultivar Golden do $4^{\circ}$ para o $5^{\circ}$ dia, o fruto manteve coloração da casca verde-amarelada. Os processos relacionados ao amadurecimento do mamão 'Gran Golden' podem estar antecipados uma vez que se observa rápida mudança de coloração da casca e de perda de firmeza. A diferença de 1 dia útil na chegada dos frutos na gôndola de comercialização torna-se relevante quanto à resistência a danos mecânicos causados pelo transporte e à própria manipulação pelo consumidor.

Um dos principais fatores relacionados à perda de firmeza na polpa de frutos é a ação de enzimas proteolíticas. Estas enzimas degradam a parede celular, levando ao amolecimento do fruto, o que o torna macio e pronto para consumo. Varoquaux \& Wiley (1994) afirmaram que as reações enzimáticas são responsáveis pela perda de firmeza da polpa, bem como pelas deteriorações sensoriais, como odor e sabor desagradáveis, e alterações da cor da casca e da polpa.

O coeficiente de correlação de Pearson demonstrou forte correlação negativa entre a firmeza da polpa e a atividade da celulase $(\mathrm{r}=-0,82)$. $\mathrm{O}$ mesmo foi observado para a $\beta$-galactosidase $(\mathrm{r}=$ -0,94) para o nível de significância de 0,001. Esses resultados demonstram que o decréscimo na firmeza dos mamões de ambas as cultivares correlaciona-se 
à atividade das enzimas celulase e $\beta$-galactosidase. Resultados semelhantes foram encontrados por Mwaniki et al. (2005) em pera, na qual observaram redução na firmeza associada ao acréscimo na atividade da $\beta$-galactosidase.

O resultado dos ensaios das atividades enzimáticas demonstrou que houve aumento na atividade da celulase e $\beta$-galactosidase de ambas as cultivares de mamão durante o período pós-colheita (Figura 1). Destaca-se aumento acentuado da atividade da celulase na cultivar Gran Golden do $4^{\circ}(7,1)$ para o $5^{\circ}$ dia (12,5 $\eta$ mol p-nitrofenol g prot $^{-1} \mathrm{~min}^{-1}$ ) (Figura 1a). O mesmo não foi observado para a cultivar Golden. A cultivar Golden apresentou aumento gradativo até o $8^{\circ}$ dia (Figura $1 \mathrm{a}$ ) com valor máximo de 12,21 $\eta$ mol p-nitrofenol g prot $^{-1} \mathrm{~min}^{-1}$. A cultivar Gran Golden apresentou valor semelhante de atividade (12,51 $\eta$ mol p-nitrofenol g prot ${ }^{-1} \mathrm{~min}^{-}$ ${ }^{1}$ ), porém o pico da celulase foi atingido no $5^{\circ}$ dia pós-colheita. $\mathrm{O}$ aumento da atividade da celulase no final do amadurecimento dos frutos, provavelmente, deve-se ao fato de que a celulose confere rigidez à parede celular por conter ligações $\beta$-(1,4)-D-glicosil nas microfibrilas de celulose e é um dos últimos componentes a ser degradado. Paull e Chen (1983) sugeriram que a celulase pode complementar a atividade da $\beta$-galactosidase em induzir a antecipação da modificação da parede celular e o amolecimento dos tecidos internos de frutos.

A atividade da $\beta$-galactosidase diferiu significativamente entre o $4^{\circ}$ e o $5^{\circ}$ dia para os mamões ‘Golden', enquanto em 'Gran Golden', a partir do segundo dia, já se observou incremento de atividade em relação ao $1^{\circ}$ dia pós-colheita. Além disso, vale ressaltar o aumento expressivo da atividade da $\beta$-galactosidase do $3^{\circ}$ para o $5^{\circ}$ dia nesta cultivar (Figura 1b). Lazan et al. (2004) afirmaram que a atividade da $\beta$-galactosidase aumenta com o amadurecimento em alguns frutos. Esse aumento na atividade enzimática está associado ao aumento da solubilidade e despolimerização das pectinas. Resultados experimentais de diversos pesquisadores indicam a importância da ação das pectinases durante o amolecimento da polpa de frutos. Lazan e Ali (1995) associaram o amolecimento do mamão da cultivar Eksotika com o aumento da atividade da $\beta$-galactosidase. Os mesmos autores sugeriram que a ação da poligalacturonase, considerada a principal enzima de modificação de parede celular, pode não ser suficiente para induzir o amolecimento do mamão durante o amadurecimento. Porém outras enzimas, como a pectinametilesterase, são associadas ao amolecimento da polpa do mamão. Fontes et al. (2008) observaram correlação entre a atividade da pectinametilesterase e a perda de firmeza na cultivar Sunrise Solo.

Paull e Chen (1983) relataram que o aumento da atividade da pectinametilesterase em mamões da cultivar Sunrise ocorre após o pico de etileno. Experimentos reportados por Nishiyama et al. (2007) sugerem que a perda de firmeza em melões 'Charentais' é dependente de etileno. Porém, existem variações entre os padrões de regulação de diferentes famílias de proteínas modificadoras de parede, de forma que alguns genes relacionados com a perda de firmeza podem ser classificados como dependentes, independentes ou parcialmente dependentes de etileno. Ayub et al. (2008) isolaram genes da poligalacturonase, xiloglucanoendotransglicosidase/hidrolase, expansina e $\beta$-galactosidase em melões. Esses genes apresentaram-se regulados diferentemente pelo etileno.

O aumento nos níveis da atividade da celulase e $\beta$-galactosidase no mamão pode estar associado à síntese de etileno. Assim, investigações adicionais com o uso de inibidores do etileno poderiam esclarecer a dependência da síntese dessas enzimas por esse hormônio.

O presente estudo indica que as cultivares Golden e Gran Golden diferem quanto ao decréscimo na firmeza da polpa, A cultivar Gran Golden apresenta firmeza aproximadamente 50\% inferior à cultivar Golden no $4^{\circ}$ dia pós-colheita. O processo de amolecimento da polpa parece relacionar-se com as enzimas celulase e $\beta$-galactosidase. Dessa forma, as enzimas celulase e $\beta$-galactosidase são indicativas do padrão de amolecimento da polpa de mamões ‘Golden’ e ‘Gran Golden'.

Os autores agradecem à Capes, ao Banco do Nordeste e à Brapex, pelo apoio financeiro, e a Frutas Herzog, pelo fornecimento dos frutos. 
TABELA 1- Firmeza (N) da polpa de mamões das cultivares Golden e Gran Golden, armazenados a 25 \pm $1^{\circ} \mathrm{C}$.

\begin{tabular}{lcccccccc}
\hline \multirow{2}{*}{ Cultivar } & 1 & 2 & 3 & 4 & 5 & 6 & 7 & 8 \\
\cline { 2 - 7 } & $104,90 \mathrm{Aa}$ & $97,80 \mathrm{Aa}$ & $85,40 \mathrm{Ba}$ & $60,60 \mathrm{Ca}$ & $7,00 \mathrm{Da}$ & $5,80 \mathrm{Da}$ & $2,20 \mathrm{Da}$ & $2,20 \mathrm{Da}$ \\
Golden & 107,80 Aa & $102,80 \mathrm{Aa}$ & $69,50 \mathrm{Bb}$ & $31,10 \mathrm{Cb}$ & $5,10 \mathrm{Da}$ & $3,50 \mathrm{Da}$ & $2,20 \mathrm{Da}$ & $2,00 \mathrm{Da}$ \\
\hline
\end{tabular}

Médias seguidas de mesma letra minúscula na coluna e maiúscula na linha não diferem entre si, pelo teste de Tukey a 5\% de probabilidade.
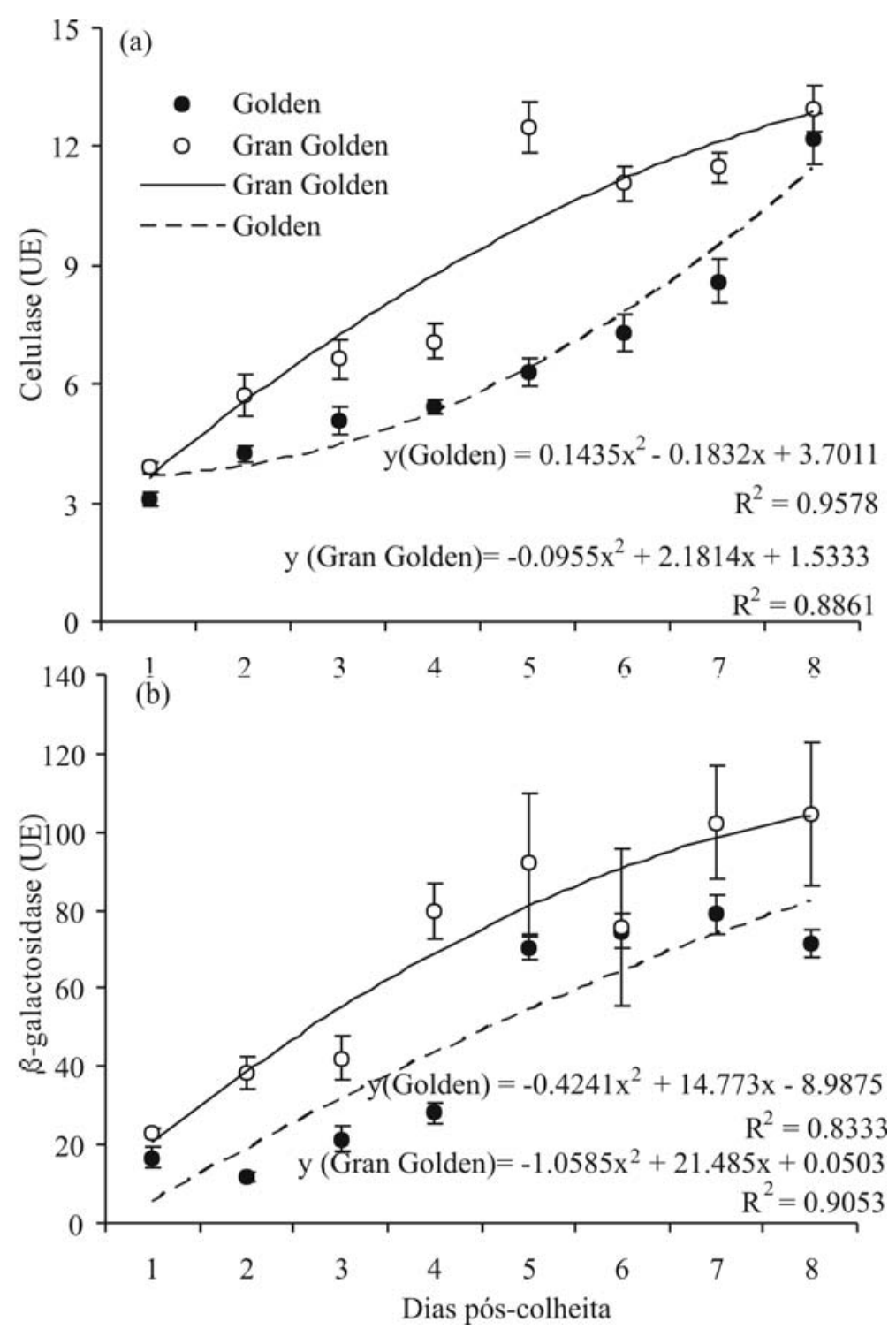

FIGURA 1- Atividades da celulase e $\beta$-galactosidase na polpa de mamões ‘Golden’e ‘Gran Golden', armazenados a $25 \pm 1^{\circ} \mathrm{C}$. Unidade enzimática (UE) corresponde à quantidade de $\eta$ mol de p-nitrofenol liberado por grama de proteína por minuto. Barras indicam o desvio-padrão das médias. 


\section{REFERÊNCIAS}

AYUB, R.; ROMBALDI, C.; LUCCHETTA, L.; GINIES, C.; LATCHÉ, A.; BOUZAYEN, M. Mechanism of melon fruit ripening and development of sensory quality. In: EUCARPIA MEETING ON GENETICS AND BREEDING OF CUCURBITACEAE, 9. 2008, Avgnon. Proceedings... Avignon: Pitrat, 2008. Disponível em: <http:\\hdl. handle. net/2174/214>. Acesso em: 22 fev. 2009.

BALASUBRAMANIAM, S.; LEE, H. C.; LAZAN, H.; OTHMAN, R.; ALI, Z. M. Purification and properties of a $\beta$-galactosidase from carambola fruit with significant activity towards cell wall polysaccharides. Phytochemistry, Amsterdan, v.66, p.153163, 2005.

BRON, I. U.; JACOMINO, A. P. Ripening and quality of 'Golden' papaya fruit harvested at different maturity stages. Brazilian Journal of Plant Physiology, Campinas, v. 18, n. 3, p. 389-396, 2006.

FONTES, R. V.; SANTOS, M. P.; FALQUETO, A. R.; SILVA, D. M. Atividade da pectinametilesterase e sua relação com a perda de firmeza da polpa de mamão cv. Sunrise Solo e Tainung. Revista Brasileira de Fruticultura, Jaboticabal, v. 30, n. 1, p. 054-058, 2008.

GROSS, K. C.; SAMS, C. E. Changes in cell wall neutral sugar composition during fruit ripening: a species survey. Photochemistry, Amsterdan, v.23, p.2457-2461, 1984.

IBGE - Instituto Brasileiro de Geografia e Estatística. 2006. Disponível em: <http\lwww.ibge.gov.br. Acesso em: 20 fev. 2009.

KARAKURT, Y.; HUBER, D. J. Activities of several membrane and cell-wall hydrolases, ethylene biosynthetic enzymes, and cell wall polyuronide degradation during low-temperature storage of intact and fresh-cut papaya (Carica papaya) fruit. Postharvest Biology and Technology, Pullman, v.28, p.219-229, 2003.

LAZAN, H. M. K. S.; ALI, Z. M. Galactosidase, polygalacturonase and pectinesterase in differential softening and cell wall modification during papaya ripening. Physiologia Plantarum, Copenhagen, v. 95, p. 106-112, 1995.

LAZAN, H.; GOH, L. Y.; ALI, Z. M. Papaya $\beta$-galactosidase/galactanase isoforms in differential cell wall hydrolisis and fruit softening during ripen- ing. Plant Physiology and Biochemistry, Paris, v.42, p.847-853, 2004.

LOWRY, O.H.; ROSERBROUGH, N.J.; FARR, A.L.; RANDALL, R.J. Protein measurement with Folin phenol reagente. Journal of Biological Chemistry, Bethesda, v.193, p.262-267, 1951.

MANRIQUE, G. D.; LAJOLO, F. M. Cell-wall polysaccharide modifications during postharvest ripening of papaya fruit (Carica papaya). Postharvest Biology and Technology, Pullman, v.33, p.11-26, 2004.

MAPA - Ministério da Agricultura, Pecuária e Abastecimento, 2007. Disponível em: <www.agricultura. gov. br > . Acesso: em 15 fev. 2009.

MWANIKI, M. W.; MATHOOKO, F. M.; MATSUZAKI, M. ; HIWASA, K.; TATEISHI, A.; USHIJIMA, K.; NAKANO, R.; INABA, A.; KUBO, Y. Expression characteristics of seven members of the $\beta$-galactosidase gene family in 'La France' pear (Pyrus communis L.) fruit during growth and their regulation by 1-methylcyclopropene during postharvest ripening. Postharvest Biology and Technology, Pullman, v. 36, p. 253-263, 2005.

NISHIYAMA, K.; GUIS, M.; ROSE, J. K. C.; KUBO, Y.; BENNETT, K. A.; WANGJIN, L.; KATO, K.; USHIJIMA, K.; NAKANO, R.; IANBA, A.; BOUZAYEN, M.; LATCHE, A.; PECH, J. C.; BENNETT, A. B. Ethylene regulation of fruit softening and cell wall disassembly in Charentais melon. Journal of Experimental Botany, Oxford, v. 58, n. 6, p. 1281-1290, 2007.

PAULL, R. E.; CHEN, N. J. Postharvest variation in cell wall degrading enzymes of papaya (Carica papaya L.) during fruit ripening. Plant Physiology, Minneapolis, v. 72, p. 382-385, 1983.

SCHREIER, P.; HARTMANN-SCHREIER, J. Properties of b--glucosidase from Carica papaya fruit. Food Chemistry, Oxford, v.26, p.201-212, 1987.

SEYMOUR, G. B.; GROSS, K. C. Cell wall desassembly and fruit softening. Postharvest News and Information, Wallingford, v.7, p.45-52, 1996.

VAROQUAUX, P.; WILEY, R. C. Biological and biochemical changes in minimally processed refrigerated fruits and vegetables. In: WILEY, R.C. (Ed.). Minimally processed refrigerated fruits \& vegetables. New York: Chapman and Hall, 1994. cap.6, p.226-268. 